\title{
Specifics of cruise tourism and features of creating a cruise tourism product
}

\author{
Natalya Logunova ${ }^{1,}$, Svetlana Kalinkina $^{2}$, Natalya Lazitskaya ${ }^{2}$, and Irina Tregulova $^{2}$ \\ ${ }^{1}$ Kerch State Marine Technological University, 82 Ordzhonikidze Str., Kerch, Russia \\ ${ }^{2}$ Sevastopol Institute of Economics and Humanities (branch) of Crimean Federal University named \\ after V.I. Vernadsky, 14-zh Astana Kesayeva str., 295007, Sevastopol, Russia
}

\begin{abstract}
The paper presents a comprehensive characteristic of cruise tourism as a special type of social and economic activity that involves the implementation of physiological, psychological and other needs of people. Cruise tourism is considered as a whole industry providing the formation, promotion and implementation of a cruise tourism product. A number of basic functions arising from the needs of its organizers and consumers is highlighted, based on the transformation of initial resources into the final product. The industry specificity of cruise tourism is reflected, and features of the cruise as a tourist product are revealed.
\end{abstract}

\section{Introduction}

The strategic goal of any state is to obtain the status of a full-fledged member of the international community, which predetermines the identification of the most effective and promising sectors of the economy, whose dynamic development contributes not only to an increase in the socio-economic level of development of a country, region or an individual enterprise, but also ensures their attractive image and a worthy place in the global market. Nowadays, priority is given to the development of those industries that, along with high economic potential, have a pronounced social orientation, based on the satisfaction of the material and spiritual needs of people, the increase in their living standards and well-being. This circumstance testifies to the growing importance of the tourism industry in general and its individual types, in particular, in the structure of the national economy, the development efficiency of which depends on the maximum possible use of the available resource potential, which ensures the achievement of competitive advantages and contributes to the socio-economic growth of the state.

Cruise tourism is not only one of the most dynamically developing, unique and popular types of business, but also has certain advantages and features that allow it to remain more stable against the background of other sectors of the economy for a long time.

\footnotetext{
*Corresponding author: natalya logunova@mail.ru
} 


\section{Results}

It should be noted that cruise tourism is a whole industry that provides the formation, promotion and implementation of a cruise tourism product, which, on the one hand, is an object of sale and purchase in the tourism market, and on the other, an object of administrative influence. At the same time, cruise tourism, which is characterized by significant capital intensity and labor intensity, is a universal type of tourism that combines almost all of its forms and contains of several of its types - recreational, sports, healthimproving, educational, congress, adventure, archeological, etc., as well as combining various options for service and recreation.

Based on the characteristics of cruise tourism, it is necessary to highlight a number of basic functions that arise from the needs of its organizers and consumers and are based on the transformation of initial resources into the final cruise product, which can be graphically represented as a pyramid shaped as a kind of cruise ship with several levels (fig. $1)$.

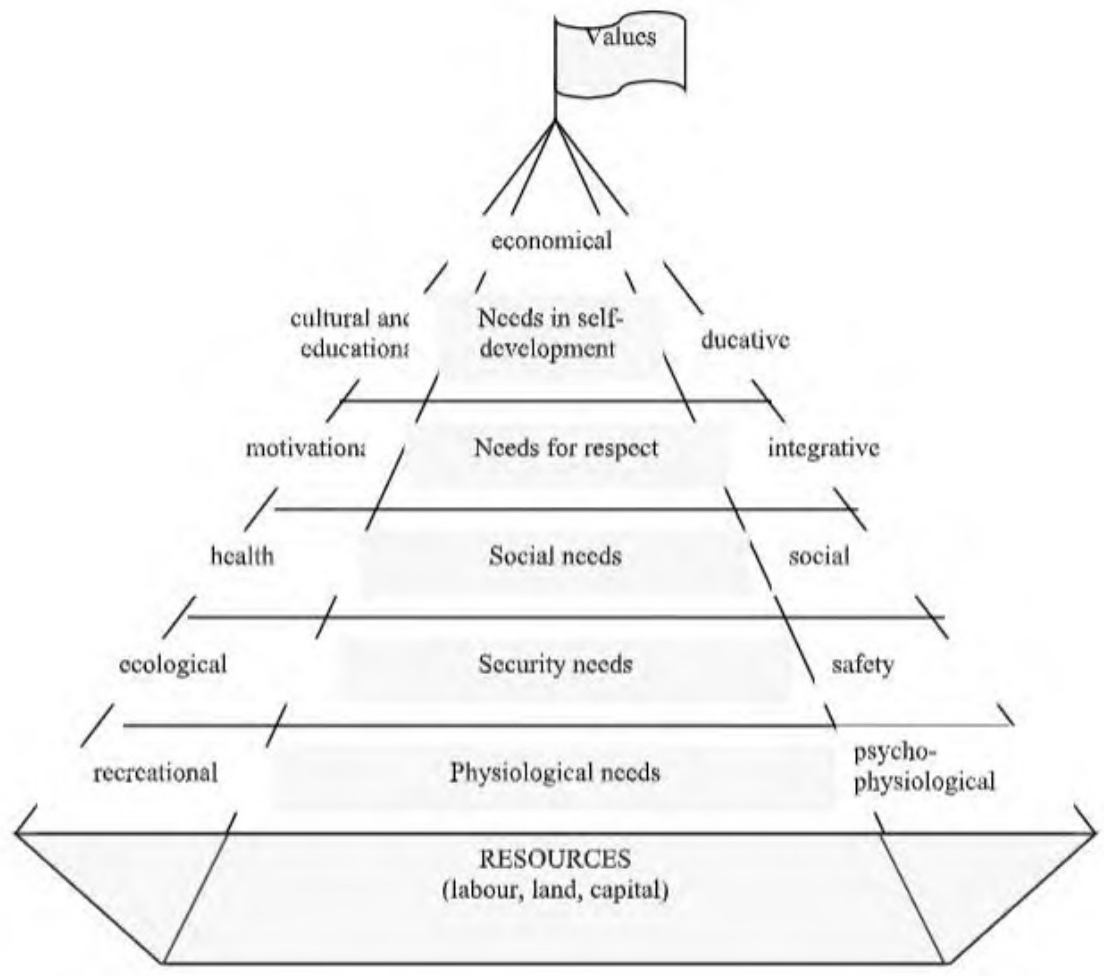

Fig. 1. Relationship of resources, needs and functions in cruise tourism.

At the base of the pyramid are resources that are the sources and prerequisites for the development of cruise tourism and ensure the realization of human needs, which is carried out at all stages of a sea voyage, from the provision of accommodation and food services (physiological needs) to the cultural and educational process (self-development of the individual), forming a system of values (physical, emotional, intellectual). The faces of the pyramid are the main functions that form the processes of creating and selling a cruise tourist product and motivating consumers to purchase it. The height of the pyramid is determined by the needs of a person, underlying his behavior, which A. Maslow divided into five groups: physiological (biological); needs for safety and protection (physiological 
and psychological); social (psychological and social); needs for respect; needs for selfdevelopment (self-expression, improvement) [1].

The principal feature that distinguishes the cruise industry and cruise tourism from other types of tourist activity is that a cruise ship, acting as a "floating bridge" and being a kind of tourist center or resort, simultaneously acts as a transport and a means of recreation. At the same time, analysts of the cruise market point out that cruise tourism is "a unique phenomenon that has little in common with the traditional concept of shipping - except that it is associated with a ship - since there is no cruise market in the sense that it is understood as applied to the rest of the shipping sectors: chartering, the market of bulk and liquid cargo, container, timber and other transportation" [2-4].

In turn, experts-practitioners of the cruise business distinguish a whole range of differences between cruise tourism and linear sea passenger transportation:

1). Travel motivation. In cruise tourism, travelling is motivated by: recreation, entertainment, sightseeing and other purposes of the trip somehow related to touristic purposes.

In the case of linear transportation by sea passenger transport, travel motivation of passengers is much wider: change of the place of residence, labor migration, a trip to another region (country) for more than a year, visiting friends and relatives, etc.

2). Social composition of passengers. The social structure of sea and cruise passenger traffic differs significantly both in terms of demographic and ethnic characteristics and in terms of income, education, occupation, etc. If the main contingent of cruise tourists are well-to-do, educated, middle-aged, family people who prefer a comfortable vacation with a rich educational program, then any person can be a passenger of an ordinary ship, regardless of his socio-economic status, age, nationality, religion, etc.

3). Range of offered passenger services. As part of the cruise tour, a diverse range of services is presented: gourmet food, comfortable accommodation, entertainment and personal recreation programs and much more, while the main type of services provided to passengers of a sea ship is transportation.

4). Design features of ships. When designing cruise ships, the central emphasis in the development of structures is huge, safe, beautiful ships of large passenger capacity with a relatively low sailing speed, but extremely resistant to waves, in contrast to liner transportation, for which minimizing the time of delivery of passengers from the port of departure to the port of destination is of paramount importance. The uneven load of energy consumption during the day leads to the provision of the ship with a powerful energyconsuming air conditioning system, which leads to a fundamentally different scheme of power units - several power plants of average power are installed that can quickly turn off or start as needed to smooth out peaks in energy consumption. Much attention is paid to the number of deck spaces, the interior of the ship, the height of the ceilings, the equipment of the lobbies, lounges, the presence of indicators and orientation diagrams, and the reduction of machine noise and hull vibration.

5). Sailing time. In cruise tourism, sailing time depends on the direction of the route, the number of ports of call, the time spent by tourists in the port and can vary significantly depending on the chosen tour and its cost. The purpose of sea passenger transportation is the fastest delivery to the destination. Therefore, the sailing time is determined by the distance from port to port and weather conditions. In addition, seasonal fluctuations in the demand for sea trips, taking into account the conditions of navigation, the vacation period, holidays, weekends and vacations, play a decisive role.

6). Geography of routes. The motivation for cruise passengers' travel determines the difference between the geography of sea cruises and the route of regular sea transportation. During the cruise, a ship visits ports located in cities and regions that are popular tourist centers; while sea passenger lines are planned to connect major business centers or places, 
between which sea communication is necessary and economically justified due to their geographical location (between the islands of the archipelago, island and mainland, etc.).

According to the Law "On the basics of tourist activity in the Russian Federation", "a tourist is a person visiting a country (place) of temporary stay in medical and healthimproving, recreational, educational, sports, professional, business and other purposes without engaging in activities related to income from sources in the country (place) of temporary stay for a period from 24 hours to 6 months in a row or carrying out at least one overnight stay in the country (place) of temporary stay" [5].

Thus, there are four main criteria for identifying a trip as a tourist trip:

1) geographical, implying departure from a permanent place of residence;

2) temporary, which determines the timing of the trip (from days to a year);

3) social, ensuring the implementation of tourist goals;

4) economic, based on the absence of paid activities in the place of visit.

Cruises as a type of travel fully meet the above criteria. Thus, the duration of the cruise is no less than 60 hours and no more than six months. Passengers of cruise ships can be both residents of the country in the territorial waters of which the cruise ship operates, and non-residents of the country of temporary residence who travel for tourist purposes and do not engage in paid activities.

The Law also provides a definition of a tourist product, which means "a complex of transportation and accommodation services provided for the total price (regardless of the inclusion in the total price of the cost of excursion services and (or) other services) under an agreement on the sale of a tourist product" [5].

Considering the cruise tourist product, it should be noted that it combines all the above services. Usually, transportation and accommodation services are provided by different companies; the first - transport ones, the second - hotels, motels, etc., i.e. enterprises on the balance sheet or in the management of which are collective accommodation facilities. Consequently, the first characteristic of a cruise as a tourist product is that the cruise ship is both a vehicle and a collective accommodation facility. Hotel and transport companies participate in the creation of a tourist product indirectly, as the cruise product is formed by the tour operator on the basis of contractual relations with other companies. The cruise organizer offers a range of services for sale in the market, including both passenger transportation and accommodation. Accordingly, the second feature of a cruise as a tourist product is that it is created in its original form by a cruise company, and not on the basis of contracts with different enterprises that supply two main services necessary to form a tourist product as a complex of services sold at a common price.

At the same time, a significant component of the cruise tourist product is the services provided by third-party organizations to the passengers of the ship on the shore (excursion services, transfers, entertainment events, etc.).

At the same time, the industry specificity of cruise tourism is that the passenger transportation and accommodation services included in it are provided to the tourist even if the passenger does not go ashore during the entire cruise.

It should be noted that the cruise product as a backbone complex of services can be represented in the form of three main subsystems [6-8]:

- services offered on the ship (accommodation, health, catering, trade, sports, etc.);

- services consumed by tourists on the shore during embarkation/disembarkation of passengers, staying at ports of call (excursion, transport, cultural and entertainment, etc.);

- services related to the promotion and sale of the cruise product and assistance to passengers in the process of organizing a trip (visa and insurance, purchase of plane or train tickets, booking excursions and hotels, providing translation services, etc.).

The offered services also include services that are included in the cruise package (accommodation in a cabin of the selected category, meals according to the system adopted 
on this ship, entertainment and sports programs on board, etc.) and services sold for a fee (medical and cosmetic, personal training in various sports with a coach, excursions and transfers, etc.). The ratio of the range of services offered to cruise passengers on the ship and on the shore depends on the cruise program, its route and the preferences of the tourist himself, for whom the cruise product is abstract in nature, consisting of benefits, the sources of which are both in material (cruise ship, infrastructure for recreation, etc.) and in immaterial (services, climatic conditions, environment) forms, which, in turn, determine the quality of the provision of cruise tourist services.

Taking into account the above, it should be emphasized that the primary features that determine the place of cruises in the specific structure of tourism are the physical and geographical characteristics of the environment in which the trip is carried out and the consumer properties of the corresponding tourist product. The technical features of the vehicles used for these purposes, which are both an object of accommodation and the provision of related services to passengers, are derived from primary - secondary features that are essential for the process of organizing this type of tourism $[9,10]$. Over the past decade, the basic consumer model of cruise tourism has multiplied across different market segments and has naturally integrated with other types of tourism. The internal structure of cruise tourism is determined by the level and areas of specialization of the cruise product and the activities of cruise companies.

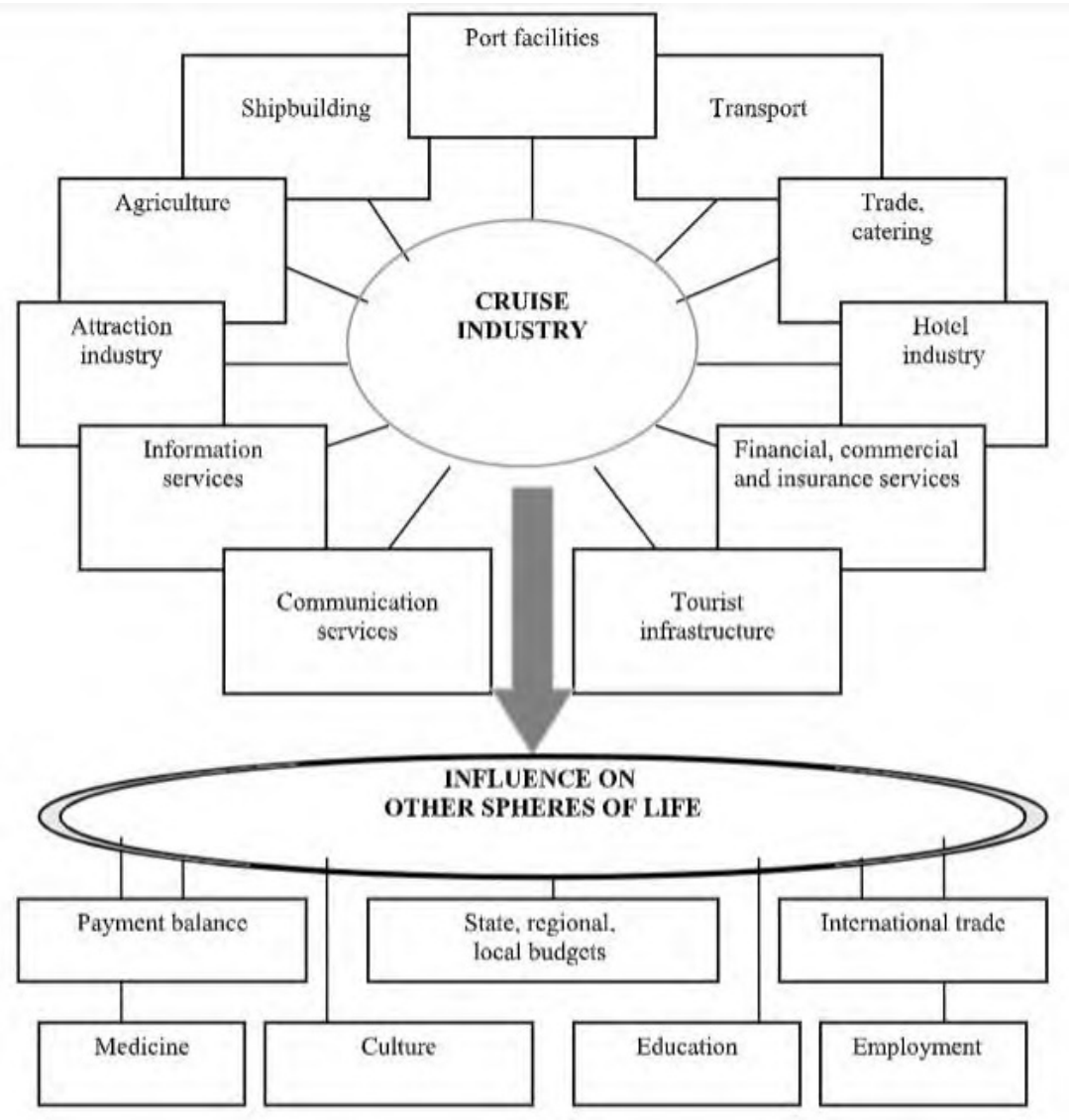

Fig. 2. The impact of the cruise industry on the economy. 
At the same time, considering the specifics of the cruise industry, it should be noted that there is a fairly wide composition of its participants, the most significant of which are (Fig. 2):

- cruise companies organizing and directly implementing cruise tours (regardless of whether they are the owners of cruise ships used for these purposes or their charterers);

- seaports providing conditions for the basing and mooring of cruise ships;

- shipbuilding and ship repair enterprises engaged in the construction of cruise ships and the provision of technical services for their maintenance;

- enterprises that are an obligatory part of the cruise tourist product from the point of view of passenger service on the shore (transport companies, excursion bureaus, catering establishments, hotels and motels, attractions and entertainment system).

Actually, the economic ties of the cruise industry can be traced back to the enterprises of the mining industry and agriculture, which are integral elements of its functioning as an integral system (for example, metal will be smelted from the mined ore for the construction of a cruise ship, the restaurant menu will include dishes from grown agricultural products and etc.).

\section{Conclusions}

Thus, the cruise industry involves all related industries in its sphere of activity - port facilities, shipbuilding, transport, tourist accommodation, communications, catering, trade, banks and financial services, entertainment and attractions, museums and other cultural objects, and provides stimulating influence on their development.

\section{References}

1. A. Maslow, The theory of human motivation ( $\mathrm{SPb}$ : Eurasia, 1999)

2. I. Leri, P. Theodoridis, The effects of the winery visitor experience on emotions, satisfaction and on post-visit behaviour intentions, Tourism Review 74(3), 480-502 (2019) DOI: 10.1108/TR-07-2018-0092

3. A. Diedrich, Cruise ship tourism in Belize: The implications of developing cruise ship tourism in an ecotourism destination, Ocean and Coastal Management 53, 234-244 (2010) DOI: 10.1016/j.ocecoaman.2010.04.003

4. G. Chase, I. Alon, Evaluating the economic impact of cruise tourism: a case study of Barbados, Anatolia: An International Journal of Tourism and Hospitality Research 13, 1, 5-18 (2002) DOI: 10.1080/13032917.2002.9687011

5. Federal Law "On the basics of tourist activity in the Russian Federation" dated 24.11.1996 N 132-FZ. Electronic resource http://www.consultant.ru/document/cons_doc_LAW_12462/

6. J.I. Castillo-Manzano, X. Fageda, F. Gonzalez-Laxe, An analysys of the determinants of cruise traffic: An empirical application to the Spanish port system, Transportation Research Part E 66, 115-125 (2014) DOI: 10.1016/j.tre.2014.03.008

7. N. Logunova, S. Kalinkina, V. Kulik, N. Lazitskaya, I. Tregulova, Peculiarities of formation and perspectives of development of the world market of the cruise industry. Topical Problems of Architecture, Civil Engineering and Environmental Economics (TPACEE 2018), E3S Web Conf. 91 (2019) DOI: $10.1051 / \mathrm{e} 3$ sconf/20199108055 
8. N. Logunova, S. Kalinkina, N. Lazitskaya, I. Tregulova, Methods and criteria for assessing the effectiveness of cruise tourism development, IOP Conference Series: Materials Science and Engineering 918(1). DOI: 10.1088/1757-899X/918/1/012213

9. B. Avdeev, A. Vyngra, S. Chernyi, Improving the Electricity Quality by Means of a Single-Phase Solid-State Transformer, Designs 4(3), $35 \quad$ (2020) doi: 10.3390/designs4030035

10. Q. Wu, Y. Gu, Y. Li, B. Zhang, S. Chepinskiy, J. Wang, et al. Position Control of Cable-Driven Robotic Soft Arm Based on Deep Reinforcement Learning, Information 11(6), 310 (2020) doi: 10.3390/info 11060310 